\title{
Sexually transmitted diseases in Canada
}

\author{
WILLIAM R BOWIE, MD, FRCPC
}

T HIS IS A FASCINATING TIME IN THE HISTORY OF SEXUALLY transmitted diseases (STD) in Canada, with exciting improvements and ongoing challenges. Some of the treatable STD have become sufficiently infrequent that it is now difficult for me to conduct clinical studies with Chlamydia trachomatis and Neisseria gonorrhoeae in the Vancouver STD clinic. This - and other examples of STD decreases (1) - could have many explanations, including availability of new antibacterials, improvements in diagnostic tests and access to them, better dissemination of relevant clinical knowledge to health care providers and changes in sexual activity and risktaking behaviours of some of the population in the era of acquired immune deficiency syndrome (AIDS).

Major problems for the 1990s: There have been advances in treatment of viral infections, but no cures. This particularly is problematic because viral infections that use sexual activity for spread are often life-long infections (eg, human immunodeficiency virus [HIV], herpes simplex virus, human papilloma virus). The decreasing rates of bacterial infections are gratifying. Rates are highest, however, in those at greatest risk of sequela, namely adolescents and young adults in whom rates are at unacceptable levels.

As noted in the accompanying article by Jessamine and Doherty (page 118), it is unlikely that we can rely on schools of medicine and related disciplines to provide trainees with adequate education and experience in management and prevention of STD. Medical school curricula are under intense pressure to decrease, rather than increase, time in lectures, and time in undergraduate years for gaining clinical skills is marginal even in major subjects.

Correspondence: Dr WR Bowie, Division of Infectious Diseases, GF Strong Research Laboratory. Room 452. D floor, 2733 Heather Street, Vancouver, British Columbia V5Z $3 J 5$. Telephone (604) 875-4147, Fax (604) 875-4013
According to current decision-making priorities, there are constraints on almost all aspects of human and financial resources that can be committed to STD and to the social and educational issues that contribute to the problem.

Academia and government in the field of STD: The academic community has shown impressive leadership in response to the STD problem. However, it often has been an uphill battle and shows signs of becoming even harder. Much was accomplished as part of the Expert Interdisciplinary Advisory Committee on STD in Children and Youth, particularly in its initial years when there was superb cooperation between academics and bureaucrats. Its term has ended, though, and the federal government appears unwilling to continue it or a similar body.

Continued efforts will require some funding and much political will. Bureaucrats, some of whom are well-meaning and supportive, and some of whom are obstructive, should recognize the future. Because of financial constraints and political realities, for the federal civil service to be effective, increasing reliance on nongovernmental organizations and cessation of the mentality that we are on opposite sides will be necessary.

Academia should strive to support publicly the positive aspects of governmental agencies and not hesitate to denounce publicly inefficiency and ineffectiveness. We must work with groups that are in a position to influence policy and priorities, such as the Royal Commission on New Reproductive Technologies (RCNRT), National Health and Welfare Research and Development Program, and elected officials. It is important to differentiate between those who may be supportive but sample the same pie and those who can help realign priorities and allocation of resources.

Opportunity to re-evaluate the allocation of resources: Partly because resources are limited, the time is 
opportune to re-evaluate the allocation of society's resources. Recently there have been repeated recommendations; for example, the Barer-Stoddart Report and the British Columbia Royal Commission on Health Care and Costs Report strongly support preventive and evaluative efforts. The RCNRT almost certainly will make similar recommendations.

The areas of healthy sexuality and of prevention, diagnosis and management of STD/HIV should emerge high on any list following priority assessment of resource allocation. Obvious reasons include: many unwanted consequences of sexual activity may be preventable; high impact on youth; severity of many sequelae; disproportionate burden of these unwanted consequences in disadvantaged groups; and disruption of many traditional sources of support in society.

\section{PRIORITIES}

Where should resources be allocated? They must be directed over a broad front, ranging from gathering data and generating new knowledge to applying it to develop and evaluate preventive programs and interventions. The former is relatively easier and is more familiar to the majority of us in infectious diseases. However, despite being more complex, the latter is the ultimate goal for health care delivery. The required multidisciplinary efforts and long term evaluations are hard enough to do even in medicine, but are much harder to do across professions. Furthermore, for those of us in academia, such research can be deadly towards promotion and tenure. We have as much education to do with our university colleagues as we do with governments and funding agencies.

The absurd separation of STD and AIDS must be terminated. The very powerful tool of modelling, which has the power to convey concepts to both academia and politicians, has been underused. Concepts like the reproductive rate of infection similarly are powerful. We have the power to continue influencing curricula and training programs, medical education priorities and content, development and evaluation of guidelines and roles in international leadership. It is our responsibility to use our resources, abilities and personal roles as advocates and researchers in the international sense and as health care providers. Space allocations limit discussion of many other priorities.

\section{PREVENTIVE EFFORTS}

Since commissions, reports and the public are vocal about preventive efforts, it is worthwhile to explore this issue further. Discussion about such efforts frequently is blocked because of a demand that efficacy be convincingly demonstrated. It is highly appropriate to demand good data on the content and evaluation of primary preventive programs. Fortunately, there are data that convincingly show there are programs of benefit in effecting change (2-4). Many who choose to ignore the data apply standards of evaluation on issues related to sexuality that they do not demand with other contentious topics (for example, different religions, our political systems and even our school systems).

I believe we must act when there are measures or interventions that we believe are logical for which there is some supportive evidence and when there is a problem or issue for which we cannot afford to maintain the status quo. We should be prepared to recommend specific interventions if defendable, and if data are not yet strong enough, then we must certainly recommend that what is known be urgently introduced in trials and evaluated. These programs must address the interrelationship of other risk-taking behaviours and the means of preventing them, paying particular attention to the social and family conditions that result in risks and in risk-taking behaviours being unevenly distributed in society.

Such an approach does not mean that we simply do something and decree it an adequate effort. Indeed, since the issue is a critical one, we should demand repeated objective assessment of what is done to facilitate further refinement and/or progress.

The expected beneficial outcomes of effective primary prevention are numerous and should include a delay in initiation of sexual debut, a decreased rate of infertility and ectopic pregnancies, and a decrease in: the risk of exposure to pathogens (by decreasing the number of partners and increasing use of barrier methods); the overall prevalence of STD; unwanted pregnancies and attendant risks; and other risk-taking behaviours. Expressed in a positive sense, there should be an increase in self-worth, communication skills, appreciation of one's sexuality and responsibility to others, and control of sexual expression and pregnancy. In the long term, and possibly in the short term, primary preventive measures should not result in greater overall cost (although it will increase some budgets disproportionately).

\section{THE FUTURE}

Though somewhat traumatic as an individual researcher, the difficulty that I have in continuing certain types of studies is a real accolade to the whole health care delivery process. However, for many pathogens or syndromes, huge gaps remain in our basic knowledge about traditional academic concerns such as pathogenicity, etiology, epidemiology, management and complications. Most of us feel comfortable pursuing these areas.

There are other equally important - and possibly ultimately more important - areas in which we are less comfortable. I believe strongly that we must provide visible leadership on the question of allocation of resources and priorities. This should be a particularly legitimate area for those of us in infectious diseases since we know the importance of preventive measures 
such as vaccines and know the impact of social and economic factors on disease transmission and prevalence. In the mid-1800s, Rudolf Virchow wrote many statements about the role of social conditions and diseases (particularly infectious diseases) including the statement "Medicine is a social science, and politics is nothing more than medicine on a grand scale" (5). There is still much truth in his premise. If we truly want to deal with many of the issues with which we are concerned, we must be prepared to challenge the system. Issues related to sexuality and STD provide cogent reasons to enter the fray.

\section{REFERENCES}

1. Gully PR. Sexually transmitted disease control. Can J Infect Dis 1992;3:42-3.

2. Fisher WA. Understanding and preventing adolescent pregnancy and STD/AIDS. In: Edwards J, Tindale RS,

Heath L, Posavac EJ, eds. Social Influence Processes and Prevention. New York: Plenum Press, 1990:77-101.

3. Fisher WA. All together now. An integrated approach to preventing adolescent pregnancy and STD/HIV infection. SIECUS Report 1990;184:1-11.

4. Rotheram-Borus MJ, Koopman C, Haigner C, Davies M. Reducing HIV sexual risk behaviors among runaway adolescents. JAMA 1991;266:1237-41.

5. Virchow R. Collected Essays on Public Health and Epidemiology, vols 1 and 2. In: Rather LJ, ed. Science History Publications, 1985. 


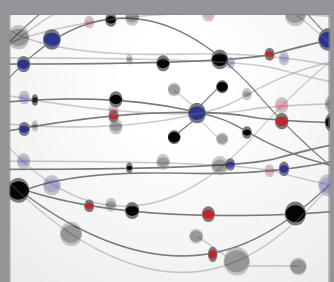

The Scientific World Journal
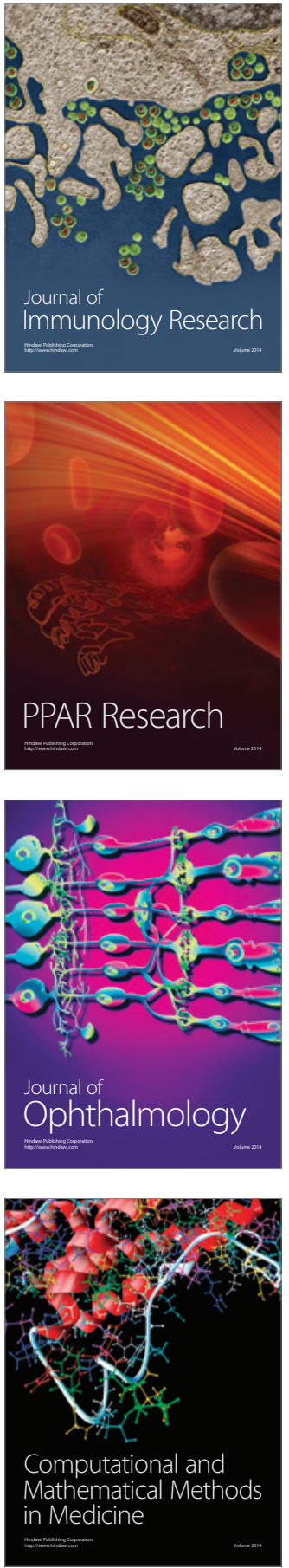

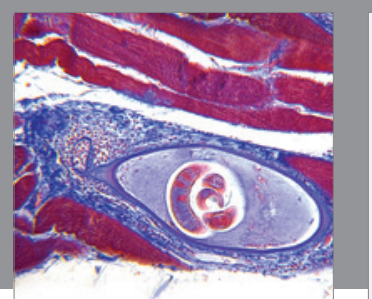

Gastroenterology Research and Practice

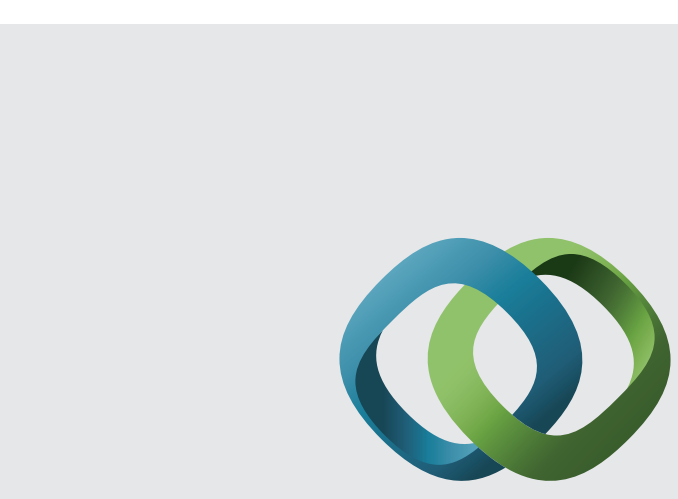

\section{Hindawi}

Submit your manuscripts at

http://www.hindawi.com
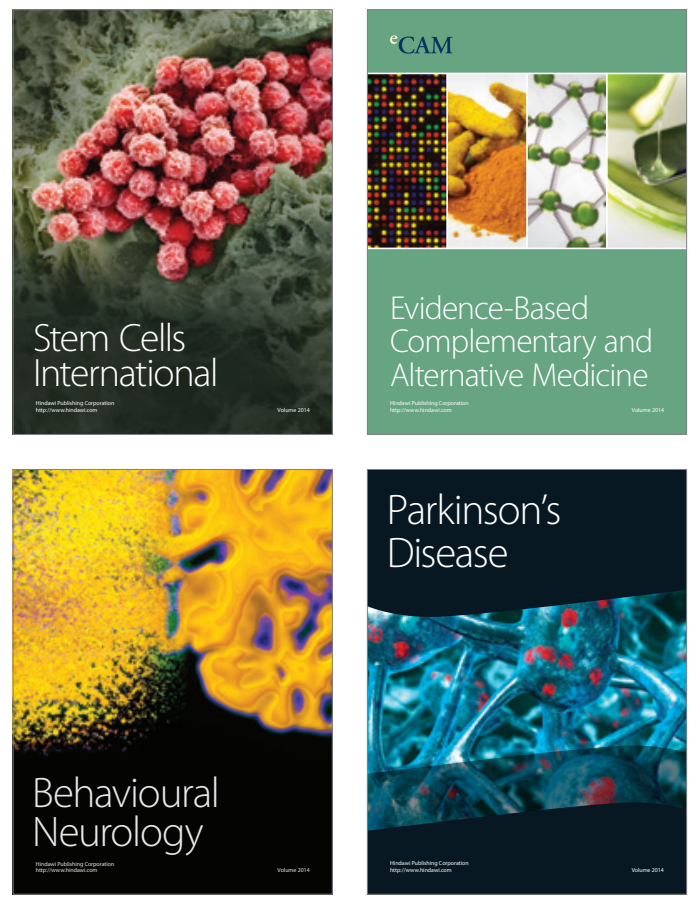
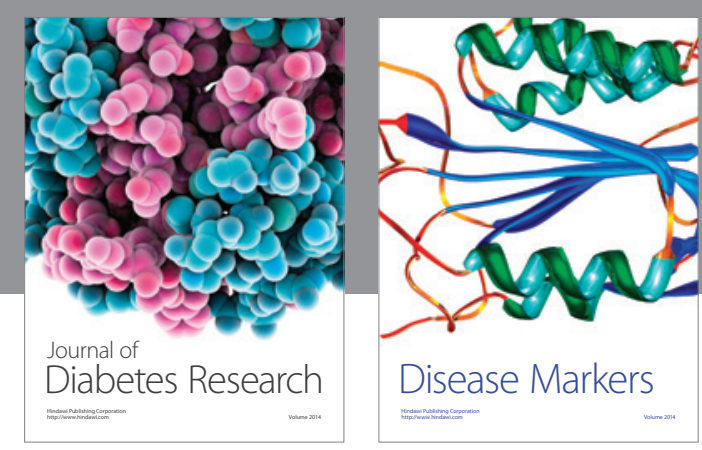

Disease Markers
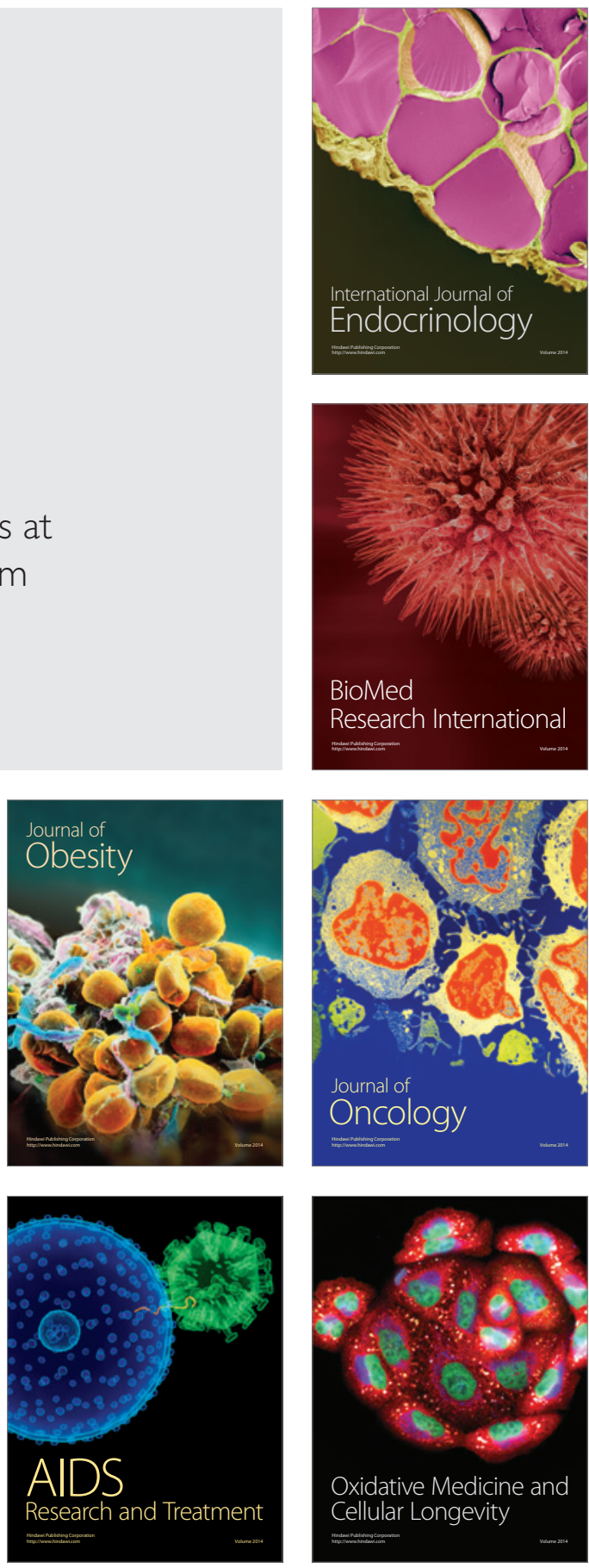